\title{
SER EN EL MUNDO SIN SER DEL MUNDO. SERENIDAD Y DIRECCIONES DEL CUIDADO EN HEIDEGGER*
}

\author{
JOSÉ MANUEL CHILLÓN \\ Universidad de Valladolid
}

\begin{abstract}
RESUMEN: La serenidad (Gelassenheit) parece abundar en la actitud resignada ante un mundo tecnificado cuya marcha irredenta solo podrá ser detenida ya solo por un dios que pueda aún salvarnos. En mi opinión, esta conocida lectura obvia la parte activa y comprometida de la serenidad cuya fertilidad emerge cuando se entiende vinculada al cuidado como esencia del Dasein. Este artículo defiende que esta interpretación es posible toda vez que se descubra la raíz cristiano-paulina de la Gelassenheit como la actitud adecuada para ser en el mundo sin ser del mundo.
\end{abstract}

PALABRAS CLAVE: serenidad; Heidegger; escatología; cristianismo paulino; técnica.

\section{Being in the world without being something of the world. Serenity and care in Heidegger}

\begin{abstract}
The serenity (Gelassenheit) seems to insist on the resigned attitude before a technified world whose unbroken march can only be stopped by a god who can still save us. In my opinion, this well-known reading obviates the active and committed dimension of serenity whose fertility emerges when it is understood linked to care as the essence of Dasein. This paper argues that this interpretation is possible whenever the Christian-Pauline root of Gelassenheit is discovered as the proper attitude to be in the world without being of the world.
\end{abstract}

KEY WORDS: serenity; Heidegger; eschatology; pauline cristianity; technology.

\section{INTRODUCCIÓN}

El concepto de serenidad aparece en la madurez filosófica de Heidegger para nombrar una actitud específicamente post-filosófica ante la técnica. Lo que este artículo quiere plantear es que esa actitud, aunque constituye poco más que un hápax legómenon en Heidegger, posee una interesante fertilidad hermenéutica que sobresale toda vez que se descubra su vinculación teológica y en especial su raíz paulina. Son ya muchas las investigaciones que porfían en la influencia del cristianismo primitivo en la filosofía de Heidegger. La propia biografía del pensador de Meskirch y sus prontas expectativas de ocupar la cátedra de filosofía católica justifican la importancia que los estudios teológicos y los autores cristianos tuvieron en su pensar juvenil ${ }^{1}$. Estudios sobre la mística medieval, sobre filosofía y fenomenología de la religión, sobre Agustín y el neoplatonismo, son algunos de

Este artículo se enmarca dentro del Proyecto de Investigación del MINECO sobre la posibilidad de la antropología en Husserl y en Heidegger cuya referencia es FF12015-63794-P

1 Aunque a finales de los 20, se desvincula de tal etiqueta poniendo en circulación lo que más me interesa en este trabajo: «Se dice que mi trabajo filosófico es fenomenología católica. Probablemente porque soy de la convicción de que también pensadores como Tomás de Aquino o Duns Escoto han entendido algo de filosofía, quizá más que los modernos». Heidegger, M., Los problemas de la fenomenología, Madrid, Trotta, 2000, p. 46. 
los textos fuente que probablemente inspiren conceptos núcleo en Heidegger como los de caída, cuidado, kairos, autenticidad... La base textual deja fuera de toda duda la influencia del cristianismo en su temprano proyecto de renovación de la fenomenología husserliana. Sin embargo, en mi opinión y, en una línea que solo ahora puedo dejar apuntada, la cosmovisión de la teología constituye en Heidegger una auténtica impronta de su pensar. De modo que los dominios de la concepción religiosa no sólo sirven para entender una parte de su primer abordaje filosófico, sino una constante de todo su proyecto que culmina, precisamente, en el póstumo sólo un dios puede aún salvarnos que quizá apunte decididamente a una pérdida definitiva de la confianza en cualquier derrotero humanista, solo redentor en apariencia. "Sin este origen teológico nunca habría alcanzado el camino del pensar ${ }^{2}$, advierte nuestro autor. La teología proyecta una alargada sombra sobre la fenomenología ${ }^{3}$. En este contexto situamos nuestro trabajo sobre la serenidad.

La serenidad, tal y como la concibió Heidegger, responde a la cuestión sobre cómo hay que vivir ante y con la técnica que, en este momento, el nuestro, parece amenazar la propia esencia del hombre. Lo que proponemos es que se amplíe el foco para descubrir cómo la serenidad podría servir para calificar cada una de las direcciones del cuidado del mundo con el que el Dasein se las ha. Si así fuera, podríamos advertir hasta qué punto la serenidad completa la angustia que sobreviene al Dasein cuando este se descubre abierto hacia un futuro que inapelablemente le es propio: la muerte. Angustia y serenidad son, en nuestra opinión, las dos actitudes que representan la paradójica existencia del ser humano. El Dasein descubre su tiempo como el tiempo del mientras tanto ante la muerte de la que tiene que hacerse cargo y, por tanto, se descubre a sí mismo como no siendo un ente más cabe los entes, sino aquel ente ocupado por el ser en cuya pregunta le va su propio ser ${ }^{4}$. Por ser cabe los entes, nunca puede rebasar el nivel de la mundanidad en la que está. Por irle el ser, ya siempre está en el contexto de la pregunta, ya siempre tiene una pre-comprensión ontológica del sentido del ser en general, ya siempre se sabe como no agotado en el aparecer sino proyectado hacia sus posibilidades. Esta doble faz ontológica es la que resume el ser del Dasein como proyecto yecto. De modo que la angustia existencial con la que el Dasein palpa la nada que le aproxima a los dominios del ser no tiene por qué llevar acoplada una

2 Heidegger, M., De camino al habla, Barcelona, Serbal, 1990, p. 95

3 Para descubrir la raíz teológica del pensamiento heideggeriano en el contexto del giro teológico de la fenomenología, puede verse WALTON, R. J., «El giro teológico como retorno de los orígenes: La fenomenología de la excedencia», en Pensamiento y cultura, 13, 2010, 18-28.

4 Por cierto, con claras resonancias de las Confesiones agustinianas (Conf. en adelante): «mihi quaestio factus sum» (Conf. X, 33). Tanto Agustín como Heidegger —explica Grondincoinciden en situar lo genuino de la existencia humana en su capacidad para preguntar. Una existencia que, fenomenológicamente descrita y fácticamente considerada, resulta precisamente estructurada por la pregunta. Cfr. Grondin, J., «Heidegger und Agustin. Zur hermeneutischen Warheit» en Richter, E., (ed.), Die Frage nach der Warheit, Frankfurt, Klostermann, pp. 150-172. Sobre la relación entre San Agustín y Heidegger, puede verse una enorme cantidad de trabajos. Citamos dos de los más significativos para el tema que nos ocupa: F. VAn Fleteren (ed.), Martin Heidegger's Interpretation of Saint Augustine, Lewiston, Edwin Mellen Press, 2005 y Coyne, R., Heidegger's Confessions. The remains of Saint Augustine in Being and Time and beyond, Chicago,: The University of Chicago Press, 2016. 
actitud ansiosa o atribulada ante el final inminente, sino muy al contrario, la paz, el sosiego o la tranquilidad que no trata de compensar el fin adveniente con ningún tipo de placebo ontológicamente degradante. La serenidad expresa mejor que nada la autenticidad de la existencia que al descubrir su esencia como cura y su sentido como Zeittlichkeit no huye del pensar para refugiarse en el mundo, para cobijarse en el puro presente, para deyectarse en el infra-nivel de las cosas. ¿Cómo vivir cuando hacerse cargo de la vida es hacerse consciente de la precariedad de lo humano, de la nimiedad de la existencia? A esa pregunta es a la que podría responder el concepto de serenidad desde esta amplia mirada que aquí proponemos.

En la serenidad resuena un concepto de temporalidad ya no en el sentido cronológico sino kairológico con un antecedente sin par en la concepción del tiempo del cristianismo primitivo ${ }^{5}$. El escrito más temprano de cuantos se incorporan al canon del Nuevo Testamento es la primera epístola a los Tesalonicenses. Las primeras comunidades cristianas viven del kerygma, de la experiencia de la resurrección de Cristo y de la esperanza en la nueva y definitiva venida. Pero estos primeros cristianos confunden lo cronológico y lo kairológico. San Pablo se lo aclara: la esperanza cristiana no tiene que ver con el tiempo en cuanto sucesión, en cuanto mensura de lo sucedido, sino con el kairós, con el tiempo propicio de la salvación. La vida del cristiano está enmarcada en el tránsito que se abre tras la primera venida en la encarnación y antes de la parusía en la que el Padre recapitulará todas las cosas. El kairós, el ahora, es el momento salvífico. Pero ese kairós acontece en un tiempo no precisamente con aspecto redentor: tribulaciones, dolores, persecuciones y angustias que, en definitiva, tientan al cristiano a abandonarse al lujo, al placer o al poder. ¿Cómo se puede vivir auténticamente en este contexto hostil? ¿Qué actitud hay que tomar con las cosas del mundo para no caer en sus redes? ¿Rechazarlas sin más? ¿Acomodarse a ellas y quemarse? San Pablo responde: hos me, como si no. Pues bien, este artículo intentará investigar en qué sentido aquella recomendación paulina contiene el mismo significado que Heidegger utiliza para definir la serenidad en el contexto del uso de la técnica en la época actual: sí y no (Als ob nicht). No debe rechazarse el progreso técnico, no hay que demonizar el uso de la técnica, sostiene Heidegger, pero debemos cuidarnos de que los objetos, de que los aparatos, de que los instrumentos no tomen cuerpo en nosotros, no nos ocupen, no nos usen. Mientras las cosas no acampen en nuestro corazón, en nuestro interior, viviremos una especie de existencia en el mundo sin ser del mundo. Sobre esto van las siguientes páginas.

\section{El PENSAR MEDitativo y La SERENIDAD}

En las lecciones de Friburgo de 1951-52, Heidegger aclara que lo más merecedor que debe pensarse en nuestro tiempo problemático es el hecho de que no pensamos ${ }^{6}$. Esta significativa deficiencia no se debe a que los hombres no se dirijan suficientemente

5 Sirve como una buena introducción a este respecto el trabajo de Pöggeler, O., El camino del pensar de Martin Heidegger, Madrid, Alianza, 1986, pp. 38-49.

6 Heidegger, M., Qué significa pensar, Madrid, Trotta, 2005, p. 17. Hemos trabajado sobre la cuestión del pensar en Heidegger en Autor., «Heidegger y lo insondable del pensar» en Logos. Anales del seminario de metafísica, 49, 2016, pp. 21-42. 
bien a aquello que da que pensar, sino al hecho de que lo que merece ser pensado se aparta del ser humano, se ha apartado desde hace tiempo sustrayéndose de una manera tal que, sin embargo, le hace conservar una peculiar e incomparable cercanía ${ }^{7}$. En nuestro tiempo, la huida de la necesidad de pensar está mutuamente implicada con el exceso de tecnificación. Por eso resulta fácil entender hasta qué punto la serenidad, como cualidad del Dasein que piensa meditativamente, se describe como la actitud correcta para con la técnica. ¿Cómo aborda este pensar pensante la técnica? De dos maneras: preguntándose por ella y respondiéndose sobre cómo situarse ante ella. Pues bien, analicemos estos dos trayectos.

En la medida en que todo preguntar es ya una búsqueda, toda pregunta supone el punto de partida de un camino, el camino del pensar. Así que sólo cabe la pregunta por la esencia de la técnica desde el pensar más pensante, desde el pensar que medita. De la misma manera que la pregunta por la metafísica sólo es posible desde un pensamiento que toma ya distancia del hacer metafísico tradicional, la pregunta por la técnica está reclamando un espacio reservado para la crítica de una civilización tecnificada que ha dejado de hacerse la pregunta por la técnica, que ha obviado pensarla. En la técnica vivimos y no sólo convivimos con ella. Pero en el hombre ha desaparecido la necesidad de preguntar por la esencia de la técnica justo en el momento en el que se ha despreocupado por el sentido, esto es, en el momento en el que se ha dejado de cuestionar no sólo por lo que ella significa sin más, sino por lo que esencialmente supone la técnica para la vida del ser humano. En $\mathrm{La}$ pregunta por la técnica ${ }^{8}$ queda expresada la situación indigente del hombre ante el bárbaro progreso de las tecnociencias. Heidegger se hace cargo del vacío del tiempo presente en el que vale con que todo funcione ${ }^{9}$. En Para qué poetas ${ }^{10}$, conferencia dictada en 1926 y dedicada a la memoria de Rilke, advierte de que el peligro de la técnica consiste en acabar con «todo ordo, toda jerarquía, porque la uniformidad del producir lo achata y de esta suerte elimina del ser el ámbito de un posible fuera de rango y reconocimiento». La inmersión en la técnica disminuye las posibilidades de que el hombre considere otro modo de situarse ante el mundo que no sea en términos de dominio y de sometimiento. Mientras más se apodera de nuestro tiempo la mentalidad tecnocientífica que termina por sitiar al propio hombre, más difícil se le hace salir de aquí. Sólo el pensar meditativo, sólo el pensar pensante puede hacerlo. Y este es su tiempo propicio. El pensar auténtico consiste en hacerse cargo meditativamente de lo ente sin quedar atrapado por ello, sin convertirse en una pieza más de un sistema que funciona y, por tanto, pensando la distancia, esto es, la diferencia que siempre tiene que darse entre el ente y el Dasein; distancia que es capacidad crítica. Lo grave entonces no es que el mundo resulte tecnificado enteramente, sino que el hombre no sepa enfrentarlo desde el pensar, desde este pensar pensante que, sin poder redimirnos del pernicioso destino de una humanidad

7 HeIdegger, M., Qué significa pensar, p. 79

8 Heidegger, M., «La pregunta por la técnica» en Conferencias y artículos, Barcelona, Serbal, 1994, p.80ss

9 Heidegger, M., «Entrevista en Der Spiegel» en La autoafirmación de la universidad alemana y otros escritos, trad. y estudio preliminar de Rodríguez, R., Madrid, Tecnos, 1989.

10 Heidegger, M., "Para qué poetas» en Caminos de Bosque, Madrid, Alianza, 1996, pp.241-289. 
tecnificada, al menos permite avisar al hombre de las arenas movedizas envolventes de un tiempo que acabará con él, justo cuando esté a punto de divinizarlo.

Abordemos ahora la segunda cuestión, la respuesta del pensar pensante a la pregunta ¿cómo hay que situarse ante la técnica? En el texto Serenidad ${ }^{11}$, Heidegger lo explica así: es necesario enfrentarse a la técnica sirviéndose de los objetos de forma apropiada pero manteniéndose libre de ellos. "Podemos decir "sí" al inevitable uso de los objetos técnicos y podemos a la vez decir "no" en la medida en que rehusamos a que nos requieran de modo exclusivo, que dobleguen, confundan y, finalmente devasten nuestra esencia» ${ }^{12}$. La conmemoración del 175 aniversario del músico Kreutzer es para Heidegger, como todo acontecimiento, una ocasión para pensar. Justo aquí, en el pensamiento sobre el pensar se detectan las carencias culturales de una época que no piensa y que ha terminado por socavar el núcleo esencial del ser humano: su propia capacidad de pensar. Una época, y esto es lo más grave, que no siente el vacío del pensar precisamente por haber acontecido en ella la apoteosis de lo que se ha tenido por pensamiento: el sometimiento de toda la realidad a cálculo, a resultado. La técnica es la expresión más prolija de este pensar que expresa la consumación de la metafísica y el final de la filosofía como ancilla de este pensar objetivante, cosificador y entitativo. Salir del bucle de este pensar no implica rechazarlo de plano, defenestrar ingenuamente el cálculo y la eficiencia o demonizar la técnica, sino pensarla de otra manera para estar ante ella también de otra manera. Decir sí y no a la técnica no es caer en una relación equívoca e insegura con los útiles, sino precisamente llenar de sentido el uso de la técnica, pensar sus límites, aprovechar sus potencialidades y seguir considerando los instrumentos como lo que son, puros medios.

La serenidad es, entonces, la actitud adecuada al pensar del ser que al mismo tiempo se muestra y se retira, explica Heidegger. Según Sloterdijk ${ }^{13}$, por medio del concepto de serenidad se recupera de alguna manera el modelo de la gracia; no está la serenidad al alcance de la voluntad humana aunque, igual que en la antropología de la gracia, esta no puede acontecer sin el esfuerzo del hombre. La serenidad sería, en este marco del pensar, una especie de don y una ingente tarea. Por eso, el pensar esencial, el pensar auténtico es el pensar que piensa el ser y, por tanto, el pensar que capta la nada en cuanto el retirarse o el ocultarse del ser que no ha sido pensado todavía. La tarea pendiente es, pues, el cambio de acorde en el pensar para que, en el mundo técnico y metafísico, sea visible translúcidamente esto que el pensar inicial de Anaximandro dejó apuntado y que sólo un lenguaje próximo al poetizar de Hölderlin puede pensar: que el olvido (el olvido del ser que ha alimentado la metafísica) no debe olvidarse. La actitud de la serenidad consiste en dejar ser al ser, permitir que brille su luz para que por ella queden iluminados los hombres y surja así otra humanidad ${ }^{14}$ capaz de ser consciente de la imperiosa necesidad de renovar

11 Heidegger, M., Serenidad. Barcelona, Serbal, 1994. Sobre la relación del pensar auténtico con la serenidad, cf. ANDERson, J. M., "On Heidegger's Gelassenheit: A Study in the Nature of Thought», in Journal of Existentialism 5, 2007, pp. 339-352.

12 Heidegger, M., Serenidad, pp. 26-27

13 Cf. Sloterdik, P., Sin salvación, Madrid, Akal, 2011, p. 45ss

14 «Este pensar está atento a la verdad del ser y de este modo ayuda al ser de la verdad a encontrar su lugar en el seno de la humanidad histórica». Heidegger, M., Qué es metafísica, Madrid, Alianza, 2014, p. 61 
una nueva relación con lo ente sin las premisas de lo calculable y sin la férrea doctrina de la productibilidad sumisa de las cosas.

Ya son varias las investigaciones que insisten en rechazar la pasividad del concepto de Gelassenheit sobre todo tratando de desvincular ese concepto de su imperdonable silencio ante los crímenes del nazismo. Lo que aquí se trata de añadir es que esa interpretación de la serenidad encuentra su fundamento originario en el ser de la existencia cristiana constituida por el estar pendiente relativo a su estar abierta, a su estar proyectada, a su encontrar sentido en el futuro de redención definitiva que ya ha acontecido en la salvación del hombre por el signo de la cruz. La existencia cristiana es una existencia en el aquí y ahora del tiempo que le toca vivir. Una existencia estructurada por la esperanza, una existencia que ontológicamente encuentra su sentido en el final adveniente de la parusía. Pero además, la serenidad pone al cristiano sobre la pista de un comportamiento práctico determinado que orienta los modos del cuidado tanto con el sí mismo como con el mundo que le rodea y con el mundo compartido ${ }^{15}$. La serenidad que rige el cuidado de sí recuerda el valor de la interioridad, de la conciencia como tabernáculo improfanable donde acontece el encuentro que hace ser a la existencia cristiana: el encuentro con Dios. La serenidad que refiere al cuidado del mundo circundante es la actitud de trato con las cosas hos me, como si no. Y por último, la serenidad relativa al mundo compartido, constituye una manera determinada de vivir la facticidad de la experiencia comunitaria. De cómo estas tres direcciones del cuidado resultan determinadas por la serenidad, van los siguientes epígrafes.

\section{SERENIDAD y CUIDADO DE Sí: EL VALOR DEL INTERIOR DEL SER HUMANO. LA ANGUSTIA}

Lo que en los primeros cristianos opone resistencia ante la imponente tentación del saeculum es la vida interior, la conciencia de una promesa de salvación que invita a sobrellevar una existencia en el mundo sin que por ello la existencia devenga mundana. Lo que en Heidegger invita a suponer una cierta redención no de la finitud (lo que sería la anulación de lo específicamente humano) sino en la finitud es, precisamente, la posibilidad de vivir con serenidad este tiempo del ya pero todavía $n o^{16}$, este tiempo atribulado minimizando la constante perturbación del existir por el pensar interior, por el pensar meditativo, por el pensar del ser en los dos posibles sentidos del genitivo. El sufrimiento, la persecución o el dolor no es algo accidental al

15 Heidegger había definido como movilidad del trato a lo propio del vivir en cuanto vivir en el mundo y es a esa movilidad a la que el joven Heidegger denomina como Sorge como un intenso andar en busca de algo, estar ocupado en algo (Aus sein auf etwas). Este cuidado que sustituye a la intencionalidad como relación fundamentalmente teórica con el mundo y que es reconducida al cómo del comportarse respecto a algo, ve al mundo desde las direcciones del cuidado que Heidegger denominará mundos del cuidado y que distingue en mundo circundante, mundo compartido, mundo del sí mismo.

16 Y recordando la impronta de la parusía, escribe: «¿Estaremos en vísperas de la transformación más enorme de la tierra y del tiempo del espacio histórico en que está suspendida? ¿Estaremos viviendo la víspera de una noche a la que seguirá un nuevo amanecer?». Heidegger, M., «La sentencia de Anaximandro» en Caminos de bosque, Madrid, Alianza, 2000, 242. 
cristiano sino que forma parte de lo sustancial de la facticidad de su existencia. Esta facticidad está vertebrada por la historicidad de una vida que tiene que decidirse constantemente por volverse a Dios (Hinwendung) volviéndose a uno mismo y a su interior y, por tanto, huir de los ídolos (Abwendung), los ídolos que tientan la existencia cristiana que provocan la dispersión en las cosas del mundo. Agustín había concretado esta caída en la concupiscencia, en la curiosidad y en la ambición por el honor ${ }^{17}$ que Heidegger resume con el vocablo Darbung o ruinancia del vivir ${ }^{18}$. Abandonar toda defluxio es exactamente la continencia a pesar de la tentación por las cosas de fuera para encontrarse con su sí mismo donde habitat veritas ${ }^{19}$. La conciencia de la tentación, y por tanto el hacerse cargo de la propia facticidad, es siempre el punto de partida de ese cuestionamiento existencial por uno mismo. Late aquí ya el concepto de serenidad. Por eso, en mi opinión, la autenticidad de la vida cristiana contagia la autenticidad de la existencia del Dasein que consiste no en curarse de las cosas del mundo sin más (porque la defluxio es también una forma de hacerlo) sino en curarse del mundo de una determinada manera. Y ahí es donde la serenidad completa la definición del cuidado como esencia de la autenticidad de la existencia en el cuidado de $\mathbf{s i ́}^{20}$. Pero, a menudo, lo acabamos de mencionar, el hombre pone en peligro su vida. ¿Cómo ha leído Heidegger esta caída del ser humano que le hace incapaz de saberse a sí mismo y de cuidarse de sí?

La finitud del Dasein es la más conspicua explicación de que el ser humano no puede explicarse por sí mismo, de que no se agota en sí. Al no agotarse en su mismidad, entiende su esencia como apertura y ésta como existencia inagotable en términos de referencia dependiente al ser. Existir no tiene que ver con la penumbra que se adivina en la interpretación existencialista y nihilista que se agota en lo óntico, sino con la claridad del ente que es estando en el claro del ser desde el que se abre como posibilidad de ser y desde el que descubre la apertura del mundo. Frente a la cerrazón del Dasein que se encuentra caído y quiere seguir estándolo al fijar su atención en las cosas y quedarse perdido en ellas en un desmoronamiento ontológico sin par, la Offenheit, debido a su ser dependiente del ser, le saca de las garras del estar encerrado en sí, del egoísmo óntico hacia una especie de donación ontológica. Por mucho que la intemperie sea existencialmente insoportable, ontológicamente detecta la obligada salida del Dasein fuera de sus seguridades como ek-sistencia cuyo sentido reside en propagarse, extenderse, prodigarse. Y así, el estado de caída no lo es por haber huido

17 Tres formas de tentación que Heidegger va analizando fenomenológicamente en los $\S 13,14$ y 15: concupiscentia carnis (el habérselas placentero con), concupiscentia oculorum (el mirar en torno curioso) y ambitio saeculi que conlleva una misera vita y una foeda jactantia. Heidegger, M., "Agustín y el neoplatonismo» en Estudios sobre mística medieval, México, FCE, 2014, pp. 13-159.

18 «Darbung ist das bezugs- und vollzugs-mäßige Grundwie des Seinssinnes von Leben». Heidegger, M., Phänomenologische Interpretationen zu Aristoteles. Einführung in die phänomenologische Forschung, Frankfurt a. M., Vittorio Klostermann, 1985, p. 90.

19 In multa defluximus (Conf. X, 29, 40). El hombre se ha fragmentado, se ha dispersado en los diverso y con ello ha desmoronado su vida.

20 El curare tiene que ver con el frui, con el uti, con la defluxus y también con la continentia. Y esta última es la que refiere al concepto de serenidad. Somos tentados en muchas ocasiones y sin cesar pero en la tentación en la que soy probado tengo el poder de explorarme a mí mismo, explica San Agustín (Conf. X, 37) 
ante los entes por temor sino que su huida es justamente hacia ellos por apego, certeza y seguridad que el Dasein no alcanza en el tiempo indigente en el que le toca vivir. El fugarse a casa propio de la caída inauténtica es, cómo no, fugarse del no en casa (Unzuhause) de la existencia auténtica que tiene que responsabilizarse de sí misma.

Las claves fundamentales del concepto de serenidad relativo al cuidado de sí pueden rastrearse, según trataremos de argumentar, en los fundamentos filosóficos de la mística medieval, tal y como los recoge Heidegger. Es el caso del concepto de recogimiento (Abgeschiedenheit) o de retraimiento (tomado de Eckhart ${ }^{21}$ ) relativos ambos al esfuerzo que el hombre tiene que hacer para girarse desde las cosas a su propio interior para descubrir así la pertenencia del alma a Dios a cuya luz todas las cosas aparecen sin la subjetividad prejuiciosa y adulterada del conocimiento humano $^{22}$. Este giro interior, este recogimiento (colligere) es tanto como el desvanecimiento de uno mismo; es la actitud kenótica de abajamiento por la que el ser humano se hace cargo de su nimiedad frente al Dios que todo lo puede y cómo no, la actitud de quien se encuentra libre respecto de todo lo creado al dejar ser a las cosas sin convertirlas en útiles para sí mismo, sin forzarlas para servir a cualquier patrón subjetivo. Es la humildad tan relacionada con el concepto de pobreza (die Armut en Heidegger) que es condición de posibilidad del acceso al fundamento. Hacernos cargo de nuestra propia nada nos libera de todos los vínculos y esclavitudes con el mundo para dejarnos en $\operatorname{Dios}^{23}$. Se trata de desprenderse de sí, de renunciar a sí para reconocerse a sí en el interior de uno mismo, en esa conversión mística que supone dejar de lado las cosas. Este podría ser el resultado del cuidado de sí en términos de serenidad ${ }^{24}$. Y esta serenidad del cuidado que descubre nuestra nada, ¿no está en las antípodas de la angustia y por tanto, según el propio discurso de Heidegger, será incapaz de percibir el sentido del ser?

La tesis de Heidegger es clara: muchos de los aspectos de la vida cotidiana en los que los hombres están embaucados (en los que los hombres han caído y en los que están atrapados) son fruto de los esfuerzos por liberarse de la angustia que

21 Según Baeza, Eckhart es fundamental para entender la coniunctio entre temporalidad y eternidad a través de un radical adelantarse a la muerte (Vorlaufen in der Tod). BAEZA, R., «Heidegger y el pensamiento medieval» en Temas Medievales 19, (2011), 115-136.

22 A pesar de que Eckhart se refiere a la relación del hombre con Dios y Heidegger a la relación del hombre con la naturaleza, según CAPUTO, J. D., The mystical element in Heidegger's thought, New York, Fordham University Press, 1986.

${ }_{23}$ «El alegrarse por ser alabado es, como tal, al tomarse a sí mismo como importante y en el nexo de la tentatio, una caída, porque ante Dios el hombre no es desde el punto de vista de su importancia, sino mera nada». HeIDEgGer, Agustín y el neoplatonismo, p. 91.

${ }_{24}$ Según Caputo: "The relationship of Being to beings in Heidegger is partly illuminated by a comparable relationship in Meister Eckhart of God to creatures» o. c., p.155. Para Davis, el concepto de Gelassenheit tal y como Heidegger lo toma de Eckhart se sitúa en otras coordenadas distintas a las de la actividad-pasividad: "Here, then, is Eckhart at his most radical, where absolute passivity paradoxically releases one into an originary freedom for "pure activity." This freedom of living without why, beyond the dictates of God's Will as well as the desire of self-will, manifests itself in a "pure [egoless and nonwilling] activity" that would lie beyond the horizon of activity and passivity, having radically stepped back out of Heidegger's "domain of the will" ». DAvis, B. W., Heidegger and the Will: On the Way to Gelassenheit, Northwestern University Press, 2007, p. 135. 
parece atrapar existencialmente al Dasein. Los descarados intentos del hombre y de la cultura por normalizar una forma de ser que prive al hombre de asumir su constitución fundamental de apertura como ser futurizo no hacen más que redundar en una existencia inauténtica, fallida, ontológicamente degradada y falseada ${ }^{25}$. La caída, léase en los términos de la cerrazón de lo humano a lo trascendente (a lo porvenir que ya siempre está) se transfigura en el anonimato, en las habladurías, en la irresponsabilidad ante un destino que nunca se puede asumir como propio. La caída es, en los propios términos de Heidegger, la fuga de sí mismo ante sí, la imposibilidad de resolverse ante su propio destino, esto es, la impropiedad (Uneigentlichkeit). Es impropia la existencia que se deja absorber por los entes a la mano impersonalizando su forma de ser (perdiéndose en el Uno) e interpretando su ser en el mundo como ser en medio de un conjunto de entes en cuanto útiles. Podríamos pues pensar que ante el Dasein se abre la posibilidad de la angustia o de la caída, la posibilidad de asumirse en la finitud radical que a cada momento de autoafirmación y realización personal anuncia el fin inapelable de la muerte, o la huida de este destino (y, por tanto la caída) en un conjunto de hazañas individuales y sociales que diluyen su responsabilidad y calman la inquietud (Die Beunruhigung) insoportable del Dasein ante la nada ${ }^{26}$. Hablar de angustia es hablar de nada ${ }^{27}$. Nada porque no es algo el ante qué de la angustia. Nada porque es totalmente insignificante lo que sucede con la

25 «El pensar en la muerte se considera públicamente miedo cobarde, triste huida del mundo. La publicidad no tolera que haya, frente al miedo a la muerte, lo que se dice valor, sino que promueve el olvido, y al tiempo lo interpreta como si fuera una ventaja del Dasein, la de la seguridad en sí mismo frente a aquel ensombrecimiento de la vida». HeIDEgGer, M., Seminarios de Zollikon, Barcelona, Herder, 2006, p. 394.

26 «Die Angst offenbart das nichts» («La angustia revela la nada») advierte Heidegger en Was ist Metaphysik?. El sentimiento relativo a esa angustia es el estado de opresión que, al no tener causa alguna, no deja de doblar sus efectos a cada paso que uno intenta preguntar por qué y sigue sin hallar respuesta. La nada por respuesta multiplica los efectos existenciales de la misma. Pero, ontológicamente, la nada por respuesta revela al Dasein, mejor que otra cosa, su inevitable vinculación al mundo y su constitutiva dependencia del ser. De la misma manera que el modo de ser de lo Vorhandenheit se revela exactamente en el momento en que el para qué del útil queda en suspenso por dejar de servir, cabe la posibilidad de que «cuando el mundo ya no tiene nada más que decirle a uno ni tampoco los demás tienen nada más que decirle a uno, el estar-siendo-enel-mundo y el mundo sin más se nos muestren». Heidegger, M., Seminarios de Zollikon, p. 365).

27 La angustia, pues, no nos pone ante un ente concreto intramundano sino ante una totalidad inabarcable como la que es el mundo, en definitiva ante la nada. Nada porque no es algo, algo concreto ante lo que debamos retroceder como sí sucede con el miedo. El miedo lo es ante los entes del mundo y, por qué no, temerlos es una forma de cuidarse de ellos. Pero la angustia es ante nada y, por eso, la angustia, cuando está, lo invade todo. El ante qué del retroceder, explica Heidegger, no es algo temible porque lo temible es siempre un ente intramundano, y aquí ante lo que se retrocede es el mundo. En definitiva, el ante qué de la angustia es el ser en el mundo por el cual se considera irrelevante todo ente intramundano que pueda causar temor. «Nada de lo que es a la mano o ante los ojos tiene que ver con aquello ante lo que se angustia la angustia». Heidegger, M., Ser y Tiempo, Madrid, RBA, 2002, p. 173. Un par de años antes, en el curso de Marburgo del semestre de verano de 1925, Heidegger había explicado ya que el miedo es un fenómeno derivado que a su vez se funda en la angustia. Cfr. Heidegger, M., Prolegómenos para una historia del concepto de tiempo, Madrid, Alianza, 2007, p. 354 ss. 
angustia una vez que se recuerda lo acontecido: "El habla cotidiana suele decir de la angustia: no era realmente nada». Nada porque la angustia hace extraños a cosas y a objetos hasta ahora familiares, carentes de relevancia y sin valor alguno y convierte en extraño a uno mismo ante sí. Nada porque no hay respuesta concluyente ante la pregunta por el qué de la angustia adelantando así que ninguna respuesta forma parte del filosofar sobre el ser, sino solo constantes y permanentes preguntas. No es extraño, entonces, tratar de huir del desasosiego permanente e insoportable que supone no hallarse a sí mismo en sí precisamente por llevar consigo aquello de lo que se querría huir. Estamos suspendidos en la angustia ${ }^{28}$ porque estamos sostenidos por la nada. Y esto es lo que es el Dasein: el estar sumergido en la nada, estar llamado a ir más allá de lo ente en una trascendencia que desborda lo concreto y enfrenta al ser de cara al tiempo que deja de lado los entes. Y dejar de lado es desasirse ante ellos, no poderse encontrar en las cosas del mundo; serenidad en definitiva. En la presencia de la nada, explica Heidegger en Qué es metafísica, enmudece toda pretensión de hablar, toda verdad en el sentido apofántico para dejarnos sin palabras. Y por eso la metafísica es el Dasein mismo, porque es la eterna pregunta que nunca descansa en un respuesta de una vez y para siempre; el fondo abismal de la nada que siempre pregunta más allá de la física. Se trata de dar espacio a lo ente en su totalidad para después abandonarse en la nada librándonos de los ídolos que tenemos y en los que solemos evadirnos.

La autenticidad de la existencia humana está a salvo de degenerar en lo existencialmente neurótico cuando se entienda la consecuente vida presente desde la serenidad. La serenidad es la disposición emocional y la actitud con la que se describe la conexión entre el hombre y los entes intramundanos y desde la que, en nuestra opinión, puede comprenderse bien el vivir cuidándose de las cosas y del mundo, lo vamos a ver ahora. Y esto significa vivir sin permitir que las cosas ocupen el lugar de la interioridad, existir hacia afuera sin quedarse fijado en las cosas del presente, sin que quepa entender la serenidad desconectada de la libertad. Es, en suma, la distancia para con las cosas; para que estas no nos tengan y sí las tengamos, para que haya espacio entre el Dasein y las cosas que permanentemente le tientan a acompasarse a su ritmo. La serenidad no es entonces un antídoto contra la angustia sino la actitud correspondiente a una forma de ser que haga soportable la existencia.

\section{SERENIDAd y CUIDAdo DEL MUNDO CIRCUNDANTE: El COMO Si NO}

Es consustancial al ser del Dasein, en cuanto ser en el mundo, una inclinación al mundo, una propensión a él. Pero esta tendencia al mundo es también una amenaza para el Dasein: el mundo puede terminar absorbiéndolo, puede terminar arrastrándolo hasta provocar el derrumbamiento ontológico de su propia vida. Parece una obra de ingeniería conceptual el delimitar bien la distancia entre el vivir en el mundo del que el Dasein tiene que ocuparse, y la constante tentación de afanarse tanto en las cosas del mundo que, al final, se produzca el extrañamiento de la existencia. La existencia auténtica, según Heidegger, tiene que ser en el

28 HeIdegger, Qué es metafísica, p. 30 
mundo sin que ello conlleve el quedarse en las cosas del mundo, confundirse con ellas. Esa insignificatividad del mundo para la existencia propia parece subvertir la significatividad (Bedeutsamkeit) como estructura del mundo. De esta manera, para una existencia auténtica el mundo sería nada. Con todo, la actitud adecuada tampoco es huir del mundo ${ }^{29}$. La deyección en las cosas y el rechazo de ellas forma parte de un mismo movimiento constitutivo de la inautenticidad de la existencia. Tener que vivir en el mundo sin dejarse atrapar por él fue también la gran cuestión práctica a la que se enfrentó el cristianismo primitivo según lo atestiguan las epístolas paulinas. Veamos qué aspectos de la lectura heideggeriana de aquellos textos sirven de base a su concepción de la serenidad.

La economía del cristianismo apunta a un tiempo, el tiempo de la salvación que es el tiempo que los cristianos, de hecho, están viviendo ${ }^{30}$. En la primera venida de Jesús ha acontecido pleroma tou chronou, la plenitud del tiempo que se produce cuando Dios envía a su hijo nacido de una mujer, nacido bajo la ley (Gal 1, 1). Se inaugura así el tiempo de una nueva historia marcada por la oportunidad definitiva del pacto de Dios con los hombres en la persona de Jesús que llega a su cénit en la cruz y que espera su culminación en la segunda venida que acontecerá en un futuro que se proclama ya próximo. La existencia acontece en este mientras tanto de un futuro que adviene. El tiempo presente ha llegado a su fin. Se abre ahora un nuevo aion constituido por la esperanza que proyecta lo que ha de venir hacia atrás, hacia lo ya sido y hacia el estar siendo. Esta reestructuración de los éxtasis temporales de la kairología cristiana es la que alimenta el concepto de temporalidad de Heidegger. Todo deviene momento salvífico para quien espera el final en el que Dios recapitulará consigo todas las cosas. Y recapitular todas las cosas es reconocer la historicidad constitutiva de todo lo acontecido pendiente de encontrar sentido en su puro transcurrir cronológico. Confesar este final donador de sentido es tanto más urgente cuanto más se sienta la tentación de claudicar ante el mundo.

El tiempo cristiano es, por tanto, el tiempo que queda hasta la venida del Señor, hasta el día de Cristo (Flp 1, 10). La parusía acontecerá como ladrón en la noche ${ }^{31}$. Por ello, el tiempo del creyente ha quedado abreviado (1 Cor 7, 29-32), y

29 De modo que no parece haber mucha evidencia textual para quienes sostienen que Heidegger, más que instigar contra las condiciones de un mundo tecnocientífico, su filosofía, especialmente su propuesta del mundo a la mano, contiene una legitimación de tal planteamiento utilitarista asentado además en su falta de claridad en la diferencia entre poiesis y praxis. Y de este modo, la serenidad no sería otra cosa que la aceptación resignada y pasiva del mundo que nos ha tocado vivir a la espera de un dios capaz de salvarnos. Puede verse en este sentido el interesante trabajo de Fernández Beites, P., «Fracaso ético de la propiedad. Alternativas a Heidegger» en Pensamiento, 67, 2011, pp. 241-263.

30 Son muy sugerentes los trabajos de CASALE, C., «La interpretación fenomenológica de Heidegger de la escatología paulina», en Teología y vida, vol. XLIX, 2008, p. 399-429; De LaRA, F., «Heidegger y el cristianismo de San Pablo y San Agustín», en Eidos, 7, 2007, pp. 28-46; Berciano, M., «Esperando su venida. Comentarios heideggerianos de escatología paulina», en Naturaleza y gracia, 2-3, 2000, pp. 429-459.

31 La condición escatológica queda descrita en 1Tes 5, 4-5 mediante antítesis como día y noche, luz y tinieblas que vuelve a aparecer en Rom 13, 12 con la contraposición entre lo pecaminoso del mundo y lo divino. Este pesimismo ante el mundo productor de esta generación depravada y perversa (Flp 2, 15) es propio del discurso apocalíptico. 
cuanto más es consciente de esta temporalidad comprimida (zusammengedrängte) más se incrementa su tribulación (Bedrägnis) ante una salvación que promete ser definitiva en un mundo que aún no transparenta esa verdad. El mundo pasa; la forma de lo mundano nunca permanece. Se trata de vivir de otra manera pero para ello el cristiano debe ser consciente del kairós en el que vive ${ }^{32}$. El cristiano, en el contexto de la comunidad, se hace cargo de esta temporalidad exactamente cuando se ocupa de saber su haber llegado a ser. A este saber es al que Pablo apela para recordar a la comunidad de Tesalónica que el tiempo de la salvación no tiene que ver con los tiempos del mundo. Si el apóstol comprometiera su palabra en fechar la venida del Señor que ardientemente espera su comunidad, estaría tergiversando un mensaje que va por otros derroteros que no son ni los comunes (como era el caso del mesianismo judío que apelaba al futuro cronológico) ni los mundanos. Si la esperanza cristiana fuera una cuestión cronológica, nada de lo vivido, nada de lo histórico, ni siquiera el presente en el que se está, tendría algún tipo de valor. Sin embargo la esperanza cristiana $^{33}$ vive el tiempo (lebt die Zeitlichkeit) sin abominar de él porque cada momento es tiempo de salvación, porque la historicidad que vertebra la movilidad de esa facticidad existencial está ligada al haber sido de la encarnación de Dios desde el haber de ser del día final. Con todo, lo que la comunidad sí puede advertir es su grado de compromiso con este momento salvífico que le toca vivir y al que Heidegger insiste en denominar facticidad, como veremos enseguida.

¿Cuál es el aspecto fundamental que determina su grado de compromiso con esa temporalidad del advenir definitivo que transparenta su esperanza? Sin duda el cuidado para con el mundo circundante. 1Cor 7, 32 sostiene que el cuidado es el sentido básico de la vida cristiana que al menos tiene que ver con la preocupación por las cosas del Señor y por las cosas del mundo. No sería una manera auténtica de existir la despreocupación por el mundo para ocuparse de las cosas de Dios, sino más bien al contrario, ocuparse de la esperanza debe redundar en algún tipo de compromiso con el mundo que sirva de testimonio ${ }^{34}$. Y esto porque algunos de los que se sienten vinculados por la inminente venida de la parusía pasan el día perdidos y holgazaneando al no haber entendido que el kairos no tiene que ver con la cronología. Su despreocupación por las contingencias de la vida les lleva al

32 El kairós cristiano es asumido por la fenomenología como el instante del fenómeno originario de la temporalidad originaria. Un instante que Aristóteles ya intuyó en el libro VI de Ética a Nicómaco. El instante (Augenblick) es «el presente que se mantiene en el estar resuelto y surge de él». Heidegger, M., Los problemas fundamentales de la fenomenología, Madrid, Trotta, 2000, p. 345. Para una mayor profundización, cf. HAAR, M., «Le moment (kairós), l’instant (Augenblick) et le temps du monde (Weltzeit) en Heidegger 1919-1929», en CourTinE, J. F., De l'herméneutique de la facticité à la métaphysique du Dasein, Paris, Vrin, 1996, pp. 67-90.

33 Que se ha denominado como espera sin espera. Cf. BAEzA, o. c., p. 117.

34 Se espera que los fieles no se aparten del mundo condenado y sin remedio (1 Cor 5 , 9-10) sino que resplandezcan en medio de ese mundo (Flp 2, 15). La propia experiencia de Pablo tiene que ver con el olvido de lo que ha dejado atrás y la salida en tensión a lo que queda por delante (Flp 3, 13). Como hará después en 1 Cor 9, 24 se trata de correr hasta la meta, una meta que está más allá de la promesa salvífica vana del presente. Los hijos de la luz, aunque incorporados a lo celeste, pisan firme en la tierra manteniéndose en expectativa al Señor que ha de venir (Flp 3, 20). Cf. Trevijano, R., Orígenes del cristianismo. El trasfondo judio del cristianismo primitivo, Salamanca, UPSA, 1996, pp. 248-260. 
extremo de no hacer nada, hablando sin decir nada y convirtiéndose en una carga onerosa para los demás (1Tes 4, 11). Quienes saben cómo esperar están en la luz; quienes haciéndolo se olvidan del mundo o se pierden en el mundo (viviendo como si Dios no existiera o como quienes viven sin esperanza) andan en las tinieblas (Gal 5, 4). Como estamos intentando mostrar, es fácil ver los antecedentes cristianos de lo que Heidegger denominará después propiedad e impropiedad de la existencia que efectivamente tienen que ver con cómo cuidarse de las cosas sin que en tal intento el Dasein sucumba a una existencia mundana ${ }^{35}$. Por eso la paz y la seguridad (1Tes 5, 3) que promete el mundo y que representa el cómo del comportarse con lo que en la vida fáctica sale al encuentro ${ }^{36}$ representa la actitud de quienes en su esperar se han visto absorbidos por lo que la vida les procura. Todavía hoy el mundo y de forma agravada la técnica prometen paz y seguridad para redimir al ser humano de toda angustia. Pero, para el análisis existenciario, la angustia es precisamente el modo del encontrarse del ser en el mundo que descubre que a uno le va inhóspitamente: es wird einem unheimlich. Unheimlich ${ }^{37}$ es la extrañeza de quien se siente fuera del ámbito familiar como un extraño o incluso un extranjero y, por tanto, puesto al descubierto, expuesto a la intemperie, sin abrigo, sin la seguridad que encuentra uno en su hogar. La angustia le recuerda que el habitar o el estar familiarizado del ser en del ser en el mundo no da pábulo a toda seguridad, sino que siempre el ser en está como no estando en casa. La autenticidad del Dasein consiste en saber y aceptar que no tiene un sitio donde reclinar la cabeza. Es inhóspito el lugar que no es lugar seguro, esto es, el lugar que aumenta el riesgo de vulnerabilidad, el lugar que no es hogar. La angustia es el modo de ser del ente que es el Dasein en cuanto deslocalizado no por no tener un lugar sino porque su lugar sea la nada. A primera vista podría parecer que la técnica abunda en esta dimensión de autenticidad de la existencia al desarraigarnos de nuestro suelo vital y descubrirnos inhóspitos, como ya hemos visto. Pero, evidentemente, no es así. La técnica acelera y deforma hasta la exacerbación esa determinación constitutiva de la inhospitalidad del Dasein ahondando en la situación existencial de angustia mientras, según su engañosa estrategia, trata de librarnos de ella impidiéndonos pensar. De esta manera, todo intento de librarse de la angustia cuenta como huida del pensar.

También lo insoportable del desasosiego constitutivo del bregar cristiano pesa como una losa que el mundo promete liberar mediante formas cada vez más sutiles de esclavitud, como denuncia Pablo. Pero, la inseguridad, la falta de certeza y la inquietud forman parte de las significatividades del mundo de la comunidad al que se incorpora el cristiano. El mundo es un lugar pero no es su hogar; no es su patria

35 «Esta peculiar relación de ser que se mantiene entre la propiedad del ser de la existencia y el procurar sucumbido ha experimentado una determinada concepción en el cristianismo y en la interpretación cristiana de la existencia». HeIDEgGer, M., Lógica. La pregunta por la verdad, Madrid, Alianza, 2015, p. 188.

36 Heidegger, M., Introducción a la fenomenología de la religión, Madrid, Siruela, 2005, p. 131

37 Según aclara Jaime Aspiunza en la traducción de las lecciones del semestre de verano de 1925, unheimlich no significaría que no tiene hogar sino que no es del hogar. Lo inhóspito es aquello de la vida que no hace hogar, que no me acoge ni recoge. unheimlich hace referencia pues a la existencia del Dasein. 
porque el cristiano espera un cielo nuevo y una tierra nueva donde habite su justicia. Vivir con esperanza, con la esperanza auténtica, exige poner los ojos en las cosas sin quedar fija la mirada. Esa provisionalidad del hombre con el mundo no es fácil de sobrellevar si no es desde la serenidad que constantemente recuerda al mundo que su existencia no es del mundo.

Y entonces ¿cómo ha de vivirse la esperanza de la parusía en el ya de la existencia? Viviendo plenamente en el mundo, viviendo las cosas del mundo como si no ${ }^{38}$. Y esto es lo que en este artículo se quiere ver como el antecedente más preclaro de la serenidad. Vivir como si no es vivir cara al futuro donde toda plenitud mundana resulta vana, donde todo hartazgo de placer deviene vaciedad, donde toda ganancia humana es considerada pérdida. En ese sentido, el cristiano vive ya no en el tiempo sino el tiempo mismo. La temporalidad proviene de esta forma de entender la peculiaridad de la existencia cristiana que no queda apegada a las cosas. El abrigo que la realidad mundana da a la intemperie de la existencia es solo provisional y, como todo lo provisional, no solo es contingente por definición, sino incapaz de proyectar algún tipo salvación en términos de sentido a lo precario del hombre. El cristiano vive en el todavía del tiempo que falta para la venida definitiva. Vivir en las cosas, permitir que la defluxio se convierta en una especie de doble naturaleza, solo sirve para ocultar los síntomas de la angustia pero no para resolver de una vez por todas el foco de la misma. De esto vive la tentación: de eliminar en apariencia lo insoportable del vacío humano para que las cosas sean la única solución a una existencia connaturalmente angustiosa. Vivir en el tiempo es vivir cegado para la temporalidad. La esperanza cristiana, sin embargo, porfía en esa necesaria desligazón entre hombre y mundo. Y su estructura, la estructura de la esperanza constituye un anticipo en toda regla de esta temporalidad de la facticidad. Una estructura que de alguna manera pone entre paréntesis el mundo en lo que podría denominarse, en mi opinión, una especie de reducción fenomenológico-moral de las cosas hacia el interior del hombre cuya esencia tiene que resistir a la irrefrenable tentación del mundo ${ }^{39}$.

Y es que la existencia cristiana es agónica ${ }^{40}$. Es la lucha contra las potencias del mundo que tientan al hombre con una fuerza incomparablemente más seductora que el mensaje de la cruz. La cruz le habla al cristiano de debilidad, de precariedad, de otra sabiduría que no es la del mundo. Y la cruz inaugura el nuevo tiempo cargando de sentido el sinsentido de la existencia que ahora, en este tiempo nuevo, está llena de una experiencia que, a los ojos del mundo, es pura locura. Que la cruz no es el destino definitivo pero vertebra toda la temporalidad de una existencia angustiosa y atribulada que no puede salvarse sin tomar conciencia de esta caída, es el contenido del kerygma que constituye el mittwelt que comparten Pablo y sus primeras comunidades. Experienciar en cristiano es sufrir la tribulación que hay

38 «Como si expresa un complejo objetual y sugiere la idea de que el cristiano debe desactivar esas referencias al mundo circundante. Este hos significa positivamente un nuevo destino que se añade. El me concierne al complejo ejecutivo de la vida cristiana. La vida cristiana no es rectilínea sino quebrada». HeIDEgGer, Introducción a la fenomenología de la religión, p. 149

39 Numquid non tentatio est vita humana super terram sine ullo interstitio? (Conf. $\mathrm{x}, 28,39)$

40 Es la tesis de Pablo, de Agustín, de Lutero y, cómo no, de Miguel de Unamuno. 
que aceptar (dégesthai). El apóstol, de hecho, vive una tribulación especial: está bajo la aflicción pero con el gozo de ser continuador de la obra de Cristo. Haciéndose eco de sus propias tribulaciones, la comunidad comparte con él la debilidad, la debilidad de la carne en la que se realiza la gracia. Y esa debilidad vivida con serenidad define mejor la existencia cristiana que la gloria ${ }^{41}$.

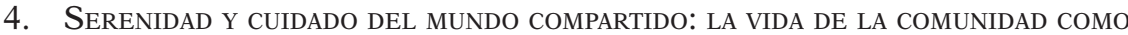 EXPERIENCIA DE LA FACTICIDAD}

La fe de los primeros cristianos es la forma de vivir su facticidad. Esta es la tesis de Heidegger. Saber de su fe es una manera privilegiada de hacer hermenéutica de la facticidad. Las comunidades se han ido constituyendo desde la experiencia del kerygma como experiencia de fe compartida que genera una determinada familiaridad (Vertrautheit) en el trato con lo religioso para los creyentes que se incorporan a ese mundo constituido por sus propias significatividades. El mundo del creyente está constituido por el plexo de significatividades con el que el cristiano se encuentra y del que es partícipe. Lo que es relevante para nuestro tema es el hecho de que la comunidad ha llegado a ser (genesthai) y se ha fortalecido en la tribulación que va irremediablemente unida a la aceptación de la proclamación del kerygma. Esta facticidad atribulada se torna en la alegría necesaria para sobrellevar los sufrimientos presentes ${ }^{42}$. Ese es el talante de la comunidad que opera en el cómo del comportarse de la vida fáctica al modo como lo ha hecho Pablo. Cada creyente recibe de la comunidad esa impronta del espíritu precisamente al participar de ese mundo compartido que es la experiencia comunitaria de la fe. Y si la tribulación connota el presente que se vive, la alegría no puede resultar del tiempo del ahora sino del kairós, de la esperanza en la redención definitiva rescatando los dos componentes de la serenidad: soportar y vivir.

Los rudimentos de la fenomenología husserliana permiten explicar la experiencia religiosa como modo de correlación intencional en el que toda experiencia es experiencia de un algo que a su vez lo es por ser el algo al que va dirigido tal experiencia. Pues bien, la facticidad de la existencia cristiana está constituida por la experiencia originaria (ursprünliche Erfahrung) de la religiosidad y lo experimentado en la experiencia religiosa (el interior de uno mismo, la vida en el mundo y la propia experiencia compartida en la comunidad). Pero esta experiencia que acontece en la vida fáctica no puede analizarse desde los protocolos teóricos de la experiencia cognoscitiva y de la epistemología clásica en términos de sujeto-objeto, en cuya estructura todavía incurre Husserl. La experiencia inmediata o la vida fáctica a la que se dirige la fenomenología encuentra en la experiencia religiosa la confirmación del blindaje que tal acontecimiento primario proyecta respecto de toda teoría.

41 La propia theologia crucis es más certera de la vida que la theologia gloriae de la dogmática cristiana, explica Lutero. La misma vida de Pablo es definida por él de un modo preteorético respecto de la vida entendida como mera secuencia de vivencias. Cf. HeIdEgGER, Introducción a la fenomenología de la religión, p. 129.

42 Y no sólo sobrellevar sino asumirlas como tales y así aunque nemo quod tolerat amat, etsi tolerare amat (Conf. X, 28, 39). Cf. HeIDEGGER, Agustín y el neoplatonismo, p. 59. 
¿Qué tiene en común el fenómeno de la vida de las lecciones del 19 y del 20 con este trabajo posterior de fenomenología de la religión? Las vivencias no ponen (en el sentido teórico-fenomenológico del carácter tético de la conciencia husserliana) sino que acontecen. Que la vida humana no se pliegue a las exigencias sistemáticas de la teoría hace comparecer a la hermenéutica como método para analizar la vitalidad que acontece en la historia. Aquí se palpa ya la consecuente transformación hermenéutica de la fenomenología. Heidegger entiende su propio lugar en la fenomenología como una dirección que debe reorientarse hacia lo que hasta ahora fue sobreentendido, obviado y subordinado a un tratamiento puramente teorético. La dinamicidad constitutiva y la riqueza de lo particular parecía poco susceptible de ser tomada como objeto de la filosofía. La fenomenología debe tematizar el acceso a ese algo dado simplemente de antemano, a la vida en sí. Ahora bien, ¿una posible investigación de este estilo no sería un contrasentido? En esto mismo repara Heidegger cuando advierte de que la más radical ciencia de la vida debería contar con una tendencia de desvivificación objetivadora y científica que, consecuentemente, abandonaría toda vitalidad ${ }^{43}$. La vida en sí, la nuestra, no es un objeto respecto del cual pudiéramos tomar distancia alguna como para estudiarlo en general. De hacerlo así, estaríamos simplificando el fenómeno mismo del existir que es siempre una tentativa para el pensar ${ }^{44}$. "Queremos empezar a conocer la vida (...) y hacerlo manteniéndonos en ella» ${ }^{45}$. La experiencia religiosa del cristianismo primitivo es modelo de lo que Heidegger quiere decir con la experiencia fáctica de la vida (der faktischen Lebenserfahrung): la experiencia de lo pre teorético. ${ }^{46}$

Lo fáctico aquí se entiende como lo histórico, como la experiencia que se da en el tiempo, como el transcurrir que invita a una nueva concepción de la historicidad desde la temporalidad. Acceder a este terreno de la facticidad ${ }^{47}$ implica encontrarse con la situación real, vital y práctica del hombre concreto y por tanto

43 «La vida no puede ser captada fácticamente en su totalidad (...) e incluso todos los aspectos, suponiendo que logren ser captados, quedan detrás de la riqueza de la vida que entretanto se ha precipitado más allá». Heidegger, M., Problemas fundamentales de fenomenología, Madrid, Alianza, 2014, 91.

${ }_{44}$ Heidegger, M., Interpretaciones fenomenológicas sobre Aristóteles, Madrid, Trotta, 2002, p. 32.

45 Heidegger, M., Problemas fundamentales de fenomenología, p. 12. El 30 de junio de 1922, Heidegger, para optar a una plaza de profesor titular en Gottinga redacta de su puño y letra un currículo en el que se ven cuáles son sus objetivos: «Las investigaciones sobre las que reposa la totalidad del trabajo realizado de cara a mis lecciones van encaminados a una sistemática interpretación ontológico fenomenológica del problema fundamental de la vida fáctica. Esta vida fáctica, conforme a su sentido ontológico, debe comprenderse como vida histórica y debe determinarse categorialmente según los modos fundamentales de comportamiento del trato con y en un mundo (circundante, compartido y propio». Cf. AdRIÁN Escudero, J., Heidegger y la genealogía de la pregunta por el ser, Barcelona: Herder, 2010.

46 "La experiencia religiosa es modelo de lo que nosotros entenderemos como vivencia de esta situación original como situación fáctica.» HEIDEGGER, M., Introducción a la fenomenología de la religión, 2005.

47 Faktizität es un término que se refiere a individual, accidental, histórico y temporal opuesto al ámbito de la Logizität que es la esfera de lo intemporal, de la validez absoluta de lo apodíctico, según el esquema neokantiano cuyas discusiones posteriores tienen que ver con la relación posible entre esos dos ámbitos disjuntos. 
obliga a hacer un sitio a la historicidad en la filosofía. Solo se puede comprender el mundo, interpretar y decidir desde una particular situación histórica ${ }^{48}$ y temporal (Jeweiligkeit). Este interés por lo preteorético había aparecido ya en su tesis de habilitación de 1915 sobre la doctrina del juicio en Duns Escoto en la que afirma que las categorías que usa el intelecto no son puras formas vacías de contenido sino que remiten a estructuras preteoréticas pertenecientes a la vida histórica. De alguna manera la haecceitas (en cuanto remite a una individualidad fáctica que escapa al control de los conceptos universales) pone a Heidegger sobre la pista de la singularidad irreductible de lo individual. Con Escoto, Heidegger se refería al espíritu vivo para designar la dimensión histórica de la existencia humana ${ }^{49}$.

Pues bien, la experiencia del cristianismo primitivo es una experiencia de la vida fáctica y un paradigma para la tarea de la filosofía en este giro hermenéutico que procede hacer desde el momento en que el saber primordial es el saber de la vida en la que ya siempre estamos y a cuyas significatividades nos incorporamos en términos de estar familiarizados con. La historia de la teología es, sin embargo, la historia del olvido de esta riqueza y de esta vivacidad inicial, de esa ingenuidad creyente y a flor de piel, de esa experiencia de fe rica todavía no objetivada o encorsetada por la dogmática posterior ${ }^{50}$. La teología se ha teorizado precisamente cuando se ha dejado conceptualizar por la metafísica entitativa y presencialista que también ha permeado el pensamiento occidental. El cristianismo dogmático y su deshistorización y desmundanización (Entgeschichtligung und Entweltung) de la facticidad es tan solo una de las consecuencias de este olvido del ser tan vertebrador de la historia de la filosofía. Y entonces, en Heidegger, desde estos primeros pasos fenomenológicos, surge la necesidad imperiosa de desmantelar la tradición para hacerse con la cosa misma ${ }^{51}$. Volver a las cosas mismas es ahora volver a pensar lo no pensado, redescubrir lo que quedó oculto desmantelando la metafísica que implica, siguiendo el doble sentido de Verwindung, tanto reponerse de la propia metafísica como remontar la metafísica para volver a pensar su origen. Desmantelar

48 «La historia nos afecta, y nosotros somos ella misma; y precisamente por no ver esto, cuando creemos poseer y dominar una consideración objetiva de la historia hasta hoy nunca alcanzada (...) hora tras hora nos golpea con la mayor fuerza la historia a nosotros mismos». HeIdegger, M., "Agustín y el neoplatonismo» o. c., p. 25.

49 La filosofía surge precisamente de esta experiencia fáctica de la vida. En el §77 de Ser y Tiempo, Heidegger recoge la opinión del Conde Yorck sobre el hecho de no poder separar la filosofía sistemática de la histórica al ser la filosofía ya siempre una manifestación de la vida.

50 Poder descubrir la riqueza de la experiencia religiosa del cristianismo naciente hizo a Heidegger volverse contra sí mismo y contra su afiliación a las tesis antimodernistas que surgen en el catolicismo presididas por la Pacendi dominici gregis de 1907 y su reconocimiento de la filosofía escolástica y de santo Tomás como maestro de la teología. Pero es el encuentro con otras tradiciones teológicas desde S. Agustín, S. Francisco, Lutero, teología protestante... que le hace experimentar esa otra dimensión del cristianismo más vital y concreta donde acontecen hombre y Dios sin ningún trámite especulativo. Se puede ver a este respecto el interesante trabajo de Adrián Escudero, J., o. c., pp. 137-223.

51 En Ontologie. vincula la tarea filosófica de remontar la tradición con la necesidad de «sacar a la luz la historia del encubrimiento». Desmontar aquí ya aparece como retornar. Heidegger, M., Ontologie. Hermeneutik der Faktizität, Frankfurt am Main, Vittorio Klostermann, 1982. 
la teología, como en su momento hizo Lutero, supone quitar toda la costra dogmática y recuperar el ardor de la vivencia religiosa tal y como fue experienciada en los albores del cristianismo. La tarea de la fenomenología de la vida religiosa es detectar la huella de esta vivencia originaria a través de la relectura, repetición de sus textos y de su dogmática. Y esto constituye lo que me parece verdaderamente sorprendente: no sólo la estrategia de la deconstrucción mediante el desmontaje de las capas teórico-dogmáticas acumuladas y solidificadas, sino que el resultado de tal reducción fenomenológica de la experiencia cristiana descubre unas características propias del creyente que vive el tiempo de la parusía que son extrapoladas para entrar con todo derecho en la determinación existenciaria del Dasein: caída, impropiedad, autenticidad y angustia... y en la última fase de su pensamiento, cuando ya no es preciso una ontologización existenciaria, la serenidad.

La fenomenología de la vida que estaba en ciernes precisaba un retorno de lo especulativo a su más acá donde se da la experiencia del encuentro entre hombre y Dios que transforma el interior del creyente, moldea su vida y determina por completo su existencia: la vita beata en el sentido agustiniano en cuanto la vida del hombre como tenencia de Dios, lo hemos visto más arriba. Interesa para el proyecto de la fenomenología no el cristianismo como sistema, sino la sola fides con la que primero Pablo y Agustín y después Lutero describían la dinámica vital del creyente. Escoto es el punto de partida del error que supone la separación tajante entre vida y doctrina, entre mística y escolástica: «La filosofía en cuanto disciplina separada de la vida es impotente; la mística en cuanto vivencia irracional carece de rumbo, no tiene fin ${ }^{52}$. La fenomenología, en definitiva, al concebirse como hermenéutica de la facticidad quiere representar este equilibrio cuya contrapartida práctica es, sin duda, la serenidad que, en mi opinión, puede quedar definida como la actitud correspondiente al pensar desde el vivir auténtico y al vivir desde el auténtico pensar.

\section{ConcLusiones}

La reflexión sobre la serenidad ofrece la posibilidad de descubrir otro modo de ser que nos permita mantener la distancia entre nosotros y las cosas lejos ya de categorías como dominación, eficacia, producción... La serenidad es el estado que resulta del estar del ser humano en el contexto del ser. Gelassenheit se traduce en inglés como letting be o dejar ser precisamente garantizando el significado de una nueva ataraxia que trata de descubrir los entes en lo que son sin ninguna imposición categorial de corte humanístico. En suma, la serenidad deja que las cosas se expresen en su ser, que no se sometan y se deformen al pensar calculador que las dispersa y las degrada. La autenticidad de la existencia humana pasa ahora por asumir su experiencia pastoral teniendo en cuenta que apacentar al ser exige hacerlo con serenidad esto es, reconociendo la insignificancia de lo óntico. Y por

52 «Philosophie als vom Leben abgelöstes, rationalistisches Gebilde ist machtlos, Mystik als irrationalistisches Erleben ist ziellos». HeIDEgger, M., Die Kategorien und Bedeutungslehre des Duns Scotus, GA 1, p. 410. 
eso, con la apoteosis de la técnica y la exacerbación del tener, la serenidad sirve de parapeto al bullir de los entes como condición necesaria para escuchar el silencio del $\operatorname{ser}^{53}$. La serenidad tiene, pues, mucho de continencia, de capacidad para abstenerse de la natural dispersión del hombre en las cosas del mundo, para evitar el dejarse llevar por los aspectos llamativos de la vida y permanecer vigilante ante cualquier atisbo de tentación que le impida ser libre de los entes. Por muchos adornos con que se revista, por muchos ropajes con los que abrigue, nada salva al hombre de su indigencia, de su debilidad, de su fragilidad. Y aquí es donde la serenidad comienza su tarea de aceptar la nimiedad de su existencia en la iluminación del ser con la consiguiente actitud de dejar ser a las cosas que a su luz se transparentan.

\section{BibliografíA}

Adrián Escudero, J. (2010). Heidegger y la genealogía de la pregunta por el ser. Barcelona: Herder.

Anderson, J. M. (2007). «On Heidegger's Gelassenheit: A Study in the Nature of Thought», in Journal of Existentialism 5, pp. 339-352.

Baeza, R. (2011). «Heidegger y el pensamiento medieval» en Temas Medievales 19, pp. 115136.

Berciano, M. (2000). «Esperando su venida. Comentarios heideggerianos de escatología paulina», en Naturaleza y gracia, 2-3, pp. 429-459.

Casale, C. (2008). «La interpretación fenomenológica de Heidegger de la escatología paulina», en Teología y vida, vol. XLIX, pp. 399-429.

Coyne, R. (2016). Heidegger's Confessions. The remains of Saint Augustine in Being and Time and beyond. Chicago: The University of Chicago Press.

De Lara, F. (2007). «Heidegger y el cristianismo de San Pablo y San Agustín», en Eidos, 7, pp. $28-46$

Caputo, J. D. (1986). The mystical element in Heidegger's thought. New York: Fordham University Press.

Chillón, J. M. (2016). «Heidegger y lo insondable del pensar» en Logos. Anales del seminario de metafísica, 49, pp. 21-42.

Davis, B. W. (2007). Heidegger and the Will: On the Way to Gelassenheit. Northwestern: University Press.

Fernández Beites, P. (2011). «Fracaso ético de la propiedad. Alternativas a Heidegger» en Pensamiento, 67, pp. 241-261.

Grondin, J., «Heidegger und Agustin. Zur hermeneutischen Warheit» en Richter, E., (ed.), Die Frage nach der Warheit. Frankfurt: Klostermann, pp. 150-172

Haar, M. (1996). «Le moment (kairós), l'instant (Augenblick) et le temps du monde (Weltzeit) en Heidegger 1919-1929», en Courtine, J. F., De l'herméneutique de la facticité à la métaphysique du Dasein. Paris: Vrin, pp. 67-90.

Heidegger, M. (2000). Los problemas de la fenomenología. Madrid: Trotta.

Heidegger, M. (1990). De camino al habla. Barcelona: Serbal.

Heidegger, M. (1982). Ontologie. Hermeneutik der Faktizität. Frankfurt am Main: Vittorio Klostermann.

53 A este respecto, Davis, o. c., concluye que "Gelassenheit albeit through a "non-willing" that seems to resonate more with the paradoxes of Zen, than with the language of beinghistorical thinking».p. 303 
Heidegger, M. (2002). Ser y Tiempo. Madrid: RBA.

Heidegger, M. (2015). Lógica. La pregunta por la verdad. Madrid: Alianza.

Heidegger, M. (2007). Prolegómenos para una historia del concepto de tiempo. Madrid: Alianza.

Heidegger, M. (2000). Los problemas fundamentales de la fenomenología. Madrid: Trotta.

Heidegger, M. (1994). «La pregunta por la técnica» en Conferencias y artículos. Barcelona: Serbal.

Heidegger, M. (1989). «Entrevista en Der Spiegel» en La autoafirmación de la universidad alemana y otros escritos, trad. y estudio preliminar de Rodríguez, R. Madrid: Tecnos.

Heidegger, M. (1996). «Para qué poetas» en Caminos de Bosque. Madrid: Alianza.

Heidegger, M. (1994). Serenidad. Barcelona: Serbal.

Heidegger, M. (2005). Introducción a la fenomenología de la religión. Madrid: Siruela.

Heidegger, M. (2002). Interpretaciones fenomenológicas sobre Aristóteles. Madrid: Trotta.

Heidegger, M.(1985). Phänomenologische Interpretationen zu Aristoteles. Einführung in die phänomenologie Forschung. Frankfurt: Vittorio Klostermann.

Heidegger, M. (2006). Seminarios de Zollikon. Barcelona: Herder.

Heidegger, M. (2014). "Agustín y el neoplatonismo» en Estudios sobre mística medieval, México, FCE, pp. 13-159

Heidegger, M. (2014). Problemas fundamentales de fenomenología. Madrid: Alianza.

Heidegger, M. (2000). «La sentencia de Anaximandro» en Caminos de bosque. Madrid: Alianza.

Heidegger, M. (2014). Qué es metafísica. Madrid: Alianza.

Heidegger, M. (2005). Qué significa pensar. Madrid: Trotta.

Pöggeler, O. (1986). El camino del pensar de Martin Heidegger. Madrid: Alianza, pp. 38-49

Sloterdik, P. (2011). Sin salvación. Madrid: Akal.

Trevijano, R. (1996). Orígenes del cristianismo. El trasfondo judío del cristianismo primitivo. Salamanca: UPSA.

Van Fleteren, F. (ed.) (2005). Martin Heidegger's Interpretation of Saint Augustine. Lewiston: Edwin Mellen Press.

Walton, R. J. (2010). «El giro teológico como retorno de los orígenes: La fenomenología de la excedencia», en Pensamiento y cultura, 13, 18-28

Universidad de Valladolid

José Manuel Chillón

Departamento de Filosofía

Prado de la Magdalena s/n 47011 Valladolid

josemanuel@fyl.uva.es

[Artículo aprobado para publicación en noviembre de 2017] 